\title{
CARACTERÍSTIQUES DE LA DEMANDA JOVE D'HABITATGE A LA REGIÓ METROPOLITANA DE BARCELONA ${ }^{1}$.
}

\author{
Carme Miralles- Guach i Carles Donat Muñoz ${ }^{2}$ \\ Institut d'Estudis Regionals i Metropolitans de Barcelona
}

Remisión Artículo: 2-10-2007

Palabras Clave: mercat de l'habitatge, règim de tinença, superfície de l'habitatge, antiguitat de l'habitatge.

Resumen: Des de la darreria dels anys noranta del segle xx el mercat de l'habitatge ha entrat en un cicle alcista sense gaire precedents en la història contemporània. Un cicle que s'ha caracteritzat per un fort augment de la població que demanda habitatges i pel gran creixement del ritme en la construcció, fet que no ha impedit, però, que els preus hagin augmentat significativament any rere any.

\section{INTRODUCCIÓ}

La població jove, aquella que té entre 18 i 34 anys, és el principal col-lectiu que incideix en la demanda d'habitatge, principalment perquè es troba en un moment del cicle vital en que s'emancipa de la llar familiar i en forma una de nova. Però també, perquè un cop emancipats, els joves continuen canviant d'habitatge, bé perquè hi ha canvis en la composició de la llar (passen de viure amb llars sense nucli a formar una parella, la parella té fills, ruptures de parella) o bé perquè es mouen a un habitatge millor.

En els darrers anys l'evolució del mercat residencial ha satisfet les necessitats d'una gran part d'aquest collectiu, a risc però d'un fort endeutament. En canvi, n'ha deixat d'altres exclosos, que o bé no s'han emancipat del domicili familiar o que encara que ho han fet viuen en unes condicions d'habitabilitat insatisfactòries. Tanmateix, continuen tenint unes necessitats d'habitatge que han de satisfer a curt termini. Aquesta diversitat de situacions és el reflex de I'heterogeneïtat socio-econòmica característica dels joves. La complexitat que se'n deriva és un dels principals trets de la interrelació entre els joves i l'habitatge i per tal d'afrontar-la, en aquest article s'analitza la demanda d'habitatge per part d'aquest col-lectiu tenint en compte les diverses situacions.

L'emancipació residencial és el punt de partida per tal d'analitzar la situació dels joves respecte a l'habitatge. Les taxes d'emancipació indiquen quin percentatge viuen en una llar pròpia i, indirectament, quin encara ho fa en el domicili familiar. Els que ja estan emancipats, en canviar d'habitatge han generat uns moviments residencials, és allò que es coneix com mobiltat residencial, i que determina la demanda d'habitatge. Tots els canvis, però, no tenen les mateixes motivacions ni tampoc les mateixes conseqüències sobre el mercat de l'habitatge. En el cas que el motiu sigui la formació d'una nova llar, bé per independitzar-se o bé per formar una nova parella, es pot parlar d'una demanda neta d'habitatges. En canvi, en el cas que hi hagi altres motivacions (canvis per millorar l'habitatge anterior, millorar l'entorn o el règim de tinença, motius laborals) les conseqüències són més complexes, ja que aquesta població, a

\footnotetext{
${ }^{1}$ La font de les dades d'aquest article és l'Enquesta de condicions de vida i hàbits de la població, 1995, 2000, 2006, IERMB. El present article és un recull adaptat al col-lectiu de població jove de la publicació: MIRALLES, C.; DONAT, C.; BARNADA, J. (2007) Habitatge i mobilitat residencial. Primeres dades de l'Enquesta de condicions de vida $i$ hàbits de la població de Catalunya, 2006. Papers. Regió Metropolitana de Barcelona. núm 46, Barcelona, Institut d'Estudis Regionals i Metropolitans de Barcelona.

${ }^{2}$ Persona de contacto IERMB, correo: iermb@uab.cat
} 
més de demandar un nou habitatge, n'ha deixat un que pot formar part de l'oferta de segona mà.

Les característiques dels habitatges on viuen els joves un cop estan emancipats ha estat el darrer element que s'ha considerat per tal d'aprofundir en la demanda d'habitatge d'aquest col-lectiu. El règim de tinença, la superfície, l'antiguitat i el nivell de satisfacció amb la casa on viuen, són algunes de les variables que permeten interpretar quines han estat les conseqüències dels processos recents del mercat de l'habitatge sobre les condicions de vida dels joves. S'han analitzat a partir de la seva evolució des de l'any 1995 fins el 2006, i comparant-les amb les característiques dels habitatges del conjunt de la població. A més, s'han diferenciat tres àmbits territorials a la Regió metropolitana, Barcelona, la primera i la segona corona ${ }^{3}$.

\section{LA POBLACIÓ JOVE I LA MOBILITAT RESIDENCIAL}

Una de les principals característiques dels joves en relació a l'habitatge, és l'alt percentatge de població d'aquest collectiu que encara no ha realitzat el seu primer canvi i que per tant no s'ha emancipat de la llar familiar. Així, entre la població més jove, la de 18 a 24 anys, les taxes d'emancipació se situen en els darrers vint-i-cinc anys en valors força baixos oscil-lant al voltant del 10\%, amb una lleugera tendència a l'alça des de que l'any 1995 s'hagués arribat al mínim (figura 1). Entre els joves de 25 a 29 anys les taxes d'emancipació són més elevades, i també presenten un lleuger augment en els primers anys del segle XXI, que es pot considerar significatiu, ja que trenquen una llarga tendència a la baixa. Entre els joves de 30 a 34 la taxa d'emancipació és la més elevada i s'observa una evolució semblant a la del grup precedent, si bé més moderada tant pel que fa als descensos dels anys noranta del segle XX com a l'augment en el darrer període. Tanmateix, s'ha de tenir en compte que aquest lleuger augment, tant entre els joves de 25 a 29 com entre els de 30 a 34, s'ha degut, principalment, al fet que la població nouvinguda, majoritàriament d'aquestes edats, està emancipada. I, en menor mesura, a un increment de les taxes d'emancipació entre la població jove que ja vivia a la Regió metropolitana i que, atès el llindar al qual havien arribat, difícilment podien disminuir més.

Figura 1: Taxes d'emancipació de la població jove de la Regió Metropolitana de

Barcelona.

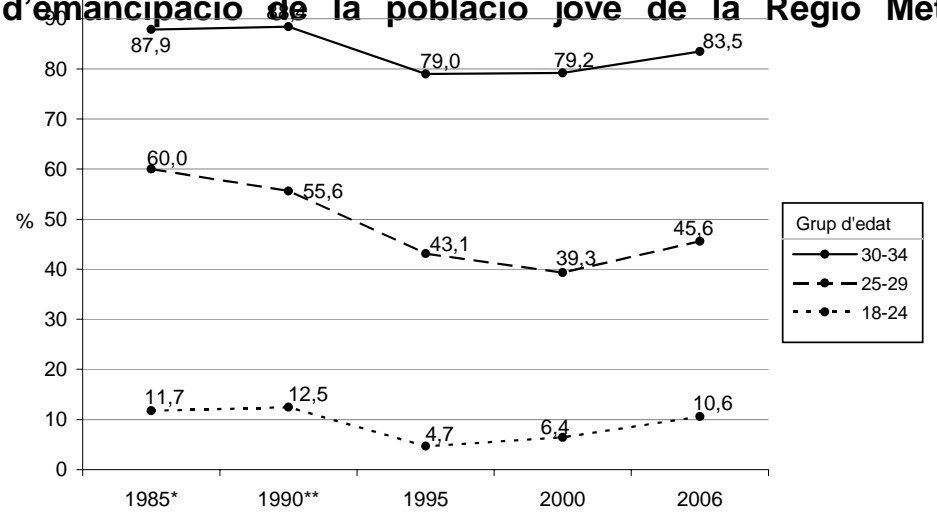

Font: IERMB. Enquesta de condicions de vida i hàbits de la població (1985, 1990, 1995, 2000, 2006)

* Dades per a l'àrea metropolitana de Barcelona (27 municipis)

* * Dades per a la Regió I (129 municipis)

\footnotetext{
${ }^{3}$ La Regió Metropolitana de Barcelona està integrada per 7 comarques i 164 municipis i coincideix amb l'Àmbit Metropolità definit pel Pla Territorial General de Catalunya. A dintre s'han distinguit tres àmbits territorials: el municipi de Barcelona; la primera corona, àmbit més proper a la ciutat central, formada pels 26 municipis que composaven l'extinta Corporació Metropolitana de Barcelona; i la segona corona, composada pels 137 municipis restants.
} 
Les baixes taxes d'emancipació contrasten entre els joves de 25 a 34 anys amb l'augment any rere any de la població que canvia d'habitatge.

Figura 2: Població emancipada de la Regió Metropolitana de Barcelona que ha canviat d'habitatge, per grups d'edat

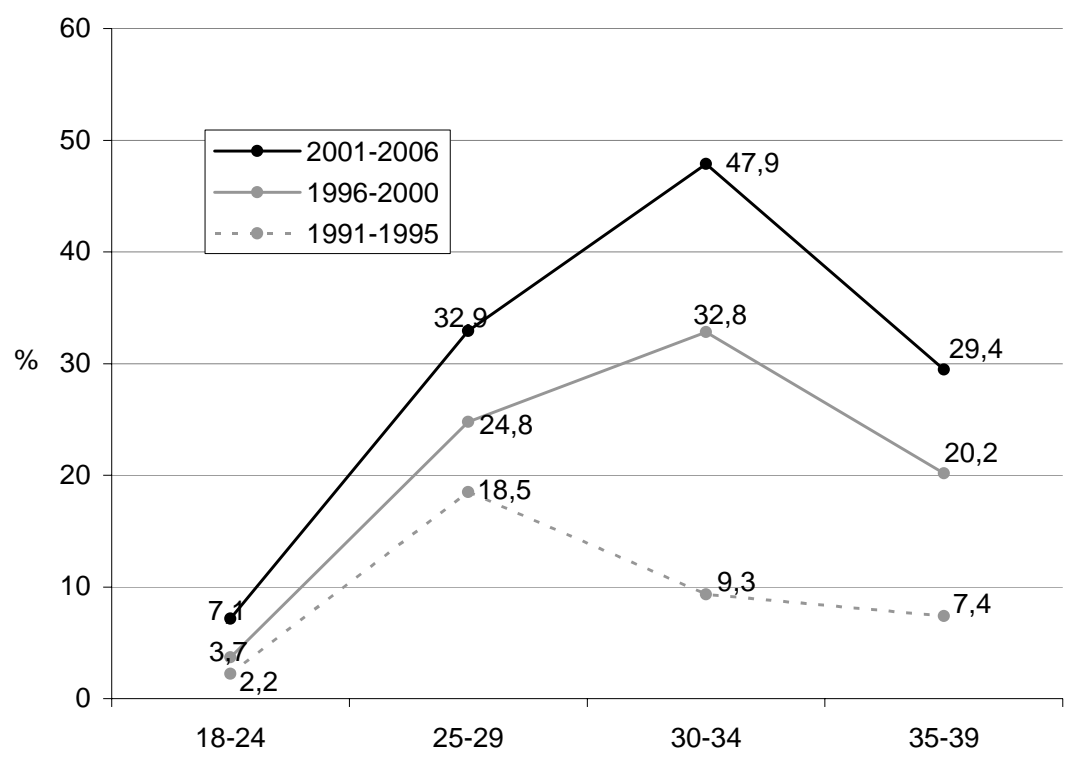

Font: IERMB. Enquesta de condicions de vida i hàbits de la població (1995, 2000, 2006)

Efectivament, tal i com s'observa a la figura 2, la mobilitat residencial de la població jove-adulta no ha fet més que augmentar a uns ritmes força intensos entre els anys noranta del segle XX $i$ els primers anys d'aquest segle. Així, si entre el 1991 i el 1995 un 18,5\% de la població de 25 a 29 anys va canviar d'habitatge, entre el 2001 i el 2006 aquest percentatge ha estat del 32,5\%. En el grup d'edat de 30 a 34 el salt ha estat més considerable i entre aquests dos períodes els valors han passat d'un $9,3 \%$ a un $47,9 \%$.

Per explicar el contrast, aparentment contradictori, d'unes baixes taxes d'emancipació i d'una elevada mobilitat residencial entre els joves, sobretot entre els joves-adults, cal tenir present quins són els motius que porten a la població a canviar d'habitatge. Així, si bé la major part d'aquests moviments tenen com a principal motivació la formació d'una nova llar, i per tant l'emancipació de la llar familiar, també hi ha una part important dels canvis que realitzen els que ja estan emancipats, l'objectiu dels quals és la millora. En concret, tal i com mostra la figura 3, pel grup d'edat de 25 a 29 anys els canvis adreçats a la formació d'una nova llar representaven el 66,3\% sobre el total de canvis en el període 1996-2000 i el 70,1\% entre els anys 2001 i 2006. Per aquest mateix grup d'edat els canvis motivats per la millora han representat un $25 \%$ en el primer període i un $21,1 \%$ en el darrer. En el grup d'edat de 30 a 34 anys les dues motivacions presenten una distribució més equilibrada. Així, la formació d'una nova llar ha estat la causa del canvi d'habitatge en un $46,9 \%$ dels casos durant els anys 19962000 i en un 45,3\% entre el 2001 i el 2006. Mentre que els motius de millora han estat els desencadenants de la mobilitat residencial en un $43,1 \%$ de les vegades durant el primer període i en un $35,8 \%$ al llarg el darrer. 
Figura 3: Motius pels quals la població jove de la Regió Metropolitana de Barcelona ha canviat d'habitatge, segons grup d'edat

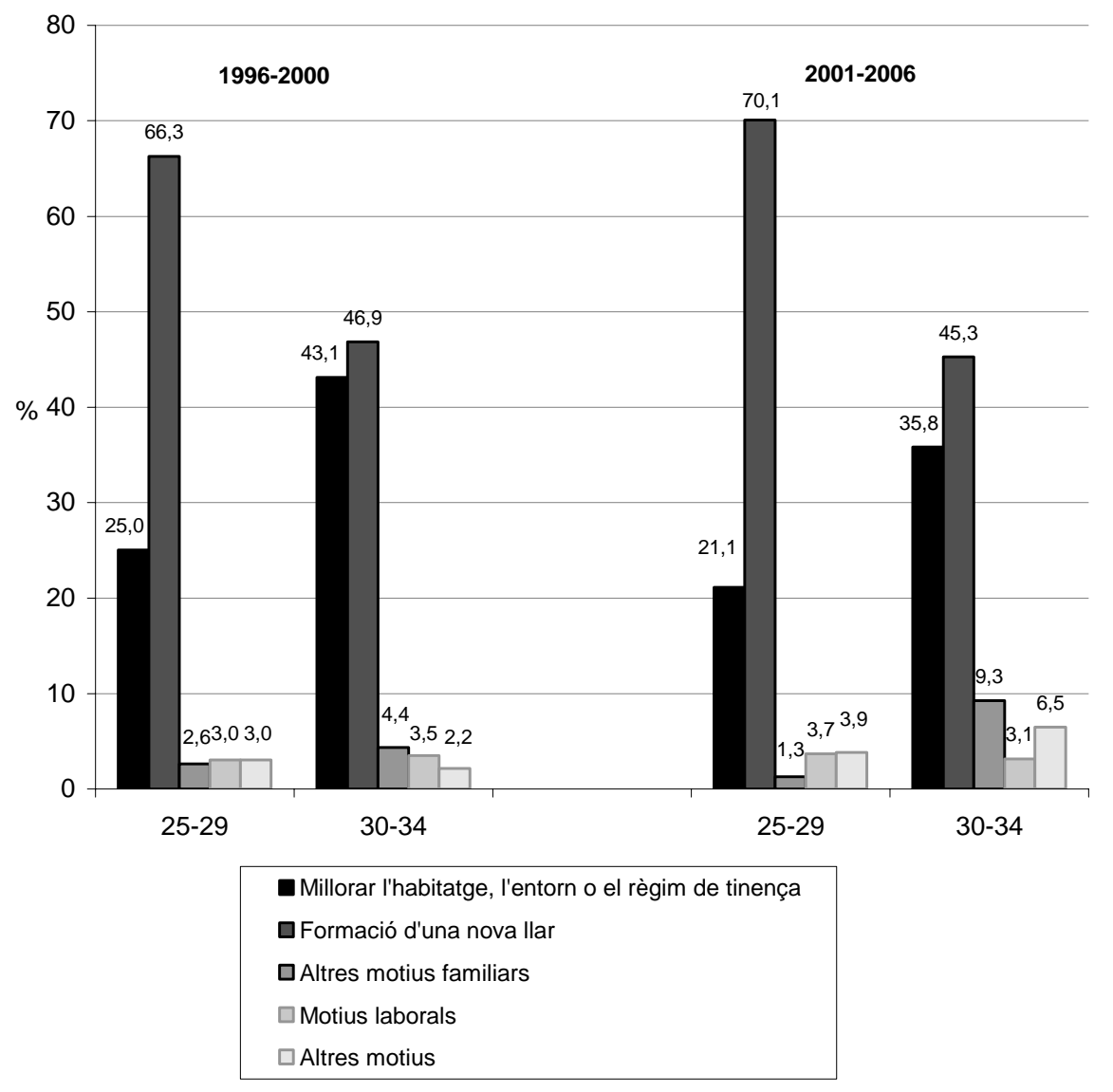

Font: Enquesta de condicions de vida i hàbits de la població (2000, 2006), IERMB

La distribució dels motius de la mobilitat residencial determina, en certa mesura, noves necessitats d'habitatge. Els canvis desencadenats per la formació d'una nova llar suposen un augment net de la demanda d'habitatges. Les altres motivacions tenen una relació més complexa amb les necessitats de nous habitatges. Els canvis que generen, des del punt de vista de la demanda, majoritàriament van més enllà de la satisfacció de les necessitats bàsiques dels individus ${ }^{4}$, perquè la població que realitza aquests canvis ja disposa d'un lloc per viure. Des del punt de vista de l'oferta, els habitatges que deixa aquesta població poden restar disponibles i entrar a formar part dels vacants. Així, un augment de la mobilitat residencial associada a aquests motius comporta noves demandes, però també noves ofertes d'habitatge de segona mà, sempre que les cases que deixa la població que es mou entrin al mercat. ${ }^{5}$

De tot plegat se'n pot deduir que la població jove és un col·lectiu força heterogeni en relació a la mobilitat residencial. Per una banda, entre els més joves, els que tenen entre 18 i 24 anys,

\footnotetext{
${ }^{4}$ Per aprofundir en la diferenciació entre les necessitats bàsiques i de millora de l'habitatge, vegeu Leal, J. i L. Cortés (1998, pp. 1-12).

${ }^{5}$ Aquesta diferenciació de les demandes s'aplica en estudis de planificació de les necessitats d'habitatge, generalment amb l'elaboració d'enquestes ad hoc. Un exemple, en què a més s'analitza l'elasticitat de cadascuna de les demandes respecte dels cicles econòmics, es pot trobar a Roca, J. (1998).
} 
predominen aquells que encara no s'han emancipat (nou de cada deu). Entre els joves de 25 a 29 és on es pot trobar el major contrast, ja que mentre que la meitat encara no s'han emancipat, un de cada vuit ja han realitzat almenys el seu segon canvi d'habitatge, per millorar. Per últim, entre els de 30 a 34 anys, un de cada cinc encara no s'han emancipat, mentre que aproximadament un de cada quatre també ha realitzat almenys el seu segon canvi de residència.

\section{PERQUĖ UNS CANVIEN D'HABITATGE I ALTRES NO?}

Com s'ha vist, les taxes d'emancipació entre la població jove de la Regió Metropolitana són força baixes. Les causes que expliquen aquest fet difereixen entre la població més jove, la de 18 a 24 anys i la població jove-adulta, aquella que en té entre 25 i 34 . Entre els primers, la baixa taxa d'emancipació és conseqüència principalment de l'allargament dels estudis i del fet d'ajornar la incorporació al mercat de treball ${ }^{6}$. En els joves de 25 a 34 anys, en canvi, els motius estarien relacionats amb altres factors. Els principals són la situació laboral d'una part d'aquest col-lectiu, ${ }^{7}$ l'esforç econòmic necessari per fer front al pagament d'un lloc per viure, el dèficit acumulat d'habitatges amb algun tipus de protecció i la importància del règim de tinença en propietat a la nostra cultura.

La combinació d'uns ingressos relativament baixos amb les elevades despeses que pot suposar el pagament d'una hipoteca o del lloguer porten a entendre l'esforç econòmic com una de les causes de la reduïda taxa d'emancipació. L'any 2006 la despesa mensual en habitatge més freqüent entre la població de 25 a 34 anys es va situar entre 301 i 600 euros. Aquesta quantitat és la que paga la meitat de la població jove-adulta de la Regió metropolitana. Per sobre, hi ha aproximadament una quarta part del collectiu que té unes despeses de 601 a 900 euros mensuals. Per sota se situa l'altra quarta part, que té unes despeses inferiors als 300 euros al mes, i entre aquests un $15 \%$ no té cap despesa ${ }^{8}$.

Si s'analitzen els ingressos de la població jove-adulta a partir de la figura 4, s'observa com al voltant d'un $56 \%$ dels joves estan per sota dels 1.050 euros al mes. Com a conseqüència, apareix un tipus d'habitatge, sovint compartit $i$ en règim de lloguer, com a primera opció d'emancipació fins que es forma una família, cosa que comporta de manera immediata la tinença d'un primer habitatge (de compra o lloguer) de caràcter transitori on no se'n valora la qualitat ni la posició urbana, sinó que s'escull quasi exclusivament en funció dels motius econòmics. El percentatge de joves amb ingressos per sota dels 1.050 euros al mes és superior entre la població que encara no viu en un habitatge propi, és a dir, que no està emancipada (el 62,8\%), que entre la que sí que ho està (el 52,3\%). De tot plegat es pot concloure que els ingressos són un dels elements que condicionen l'emancipació.

\footnotetext{
${ }^{6}$ Veugeu COSTAS, A. (2007), p. 46.

7 Segons dades de l'Enquesta de condicions de vida i hàbits de la població, la proporció de la població jove emancipada de 25 a 34 anys que treballa a la Regió metropolitana ha passat del 64,9\% el 1995 al 86,3\% el 2006. Paral-lelament, també ho ha fet la proporció de gent assalariada amb contracte temporal, que ha passat del voltant d'un $7,5 \%$ a prop d'un $22,0 \%$ el 2006.

${ }^{8}$ Font: Enquesta de condicions de vida i hàbits de la població, 2006, IERMB.
} 
Figura 4: Ingressos nets mensuals de la població de 25 a 34 anys de la Regió Metropolitana de Barcelona, segons estat de l'emancipació (2006)

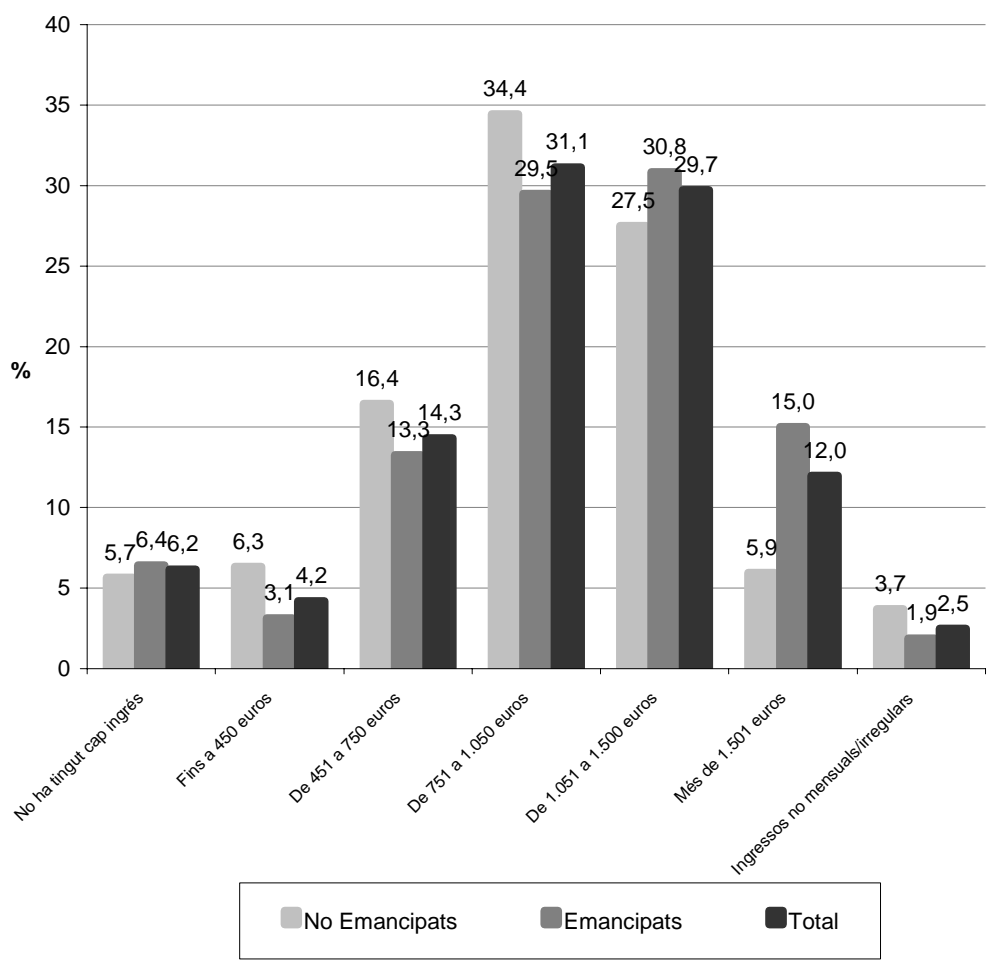

Font: Enquesta de condicions de vida i hàbits de la població (2006), IERMB

Un altre dels elements que expliquen que els joves tinguin tantes dificultats per emancipar-se és el dèficit acumulat d'habitatges amb algun tipus de protecció. El context d'evolució ascendent de l'esforç econòmic necessari per accedir a un habitatge contrasta amb la insuficiència del parc d'habitatges existent amb algun règim de protecció o de tipus dotacional ${ }^{9}$. Aquest és un dèficit que des del punt de vista de l'oferta es va originar a mitjan anys noranta quan es va entrar en un període de reducció en la seva promoción ${ }^{10}$. Només en els darrers anys, diversos ajuntaments metropolitans han iniciat polítiques específiques d'habitatges dotacionals de lloguer per a joves. Unes polítiques que es concreten en edificis amb pisos de reduïdes dimensions per a ús temporal fins que els joves disposin de les condicions necessàries per accedir a un segon habitatge.

Si bé el dèficit d'habitatges amb protecció i l'esforç econòmic necessari per poder tenir un lloc on viure expliquen part del retard de l'emancipació, també existeixen altres causes, com per exemple la manca d'estabilitat laboral que pateix aquest col.lectiu i alguns factors de tipus cultural. Entre aquests darrers destaca la preferència per la compra i la poca oferta de lloguer associada. Tot i que en els darrers anys hi ha hagut un augment de la proporció de

\footnotetext{
${ }^{9}$ S'enten per habitatge dotacional aquell que es construeix en sòl públic per a equipaments i que està destinat $i$ adaptat per a col-lectius amb necessitats especials (p.e., gent gran i joves)

${ }^{10}$ Per exemple, a l'àmbit de la Mancomunitat de Municipis de l'Àrea Metropolitana de Barcelona entre els anys $1995 \mathrm{i}$ 2005 l'habitatge protegit ha passat de representar més del 50\% de la promoció total a menys del 6\%. (vegeu ÀMB. Revista de l'Àrea Metropolitana de Barcelona, 2007).
} 
població jove-adulta que viu de lloguer, la compra continua essent el règim majoritari a la Regió metropolitana.

El fet de comprar un habitatge implica en molts casos la necessitat d'estalviar per poder pagar una entrada, i són molts els joves que, tot $i$ trobar feina, allarguen la permanència a casa dels pares per poder fer-ho. A més, tant les polítiques públiques, fonamentalment les fiscals, com les entitats financeres, han fomentat la compra de l'habitatge. Només en els darrers anys s'han iniciat algunes polítiques públiques d'ajut i foment al lloguer destinades tant als propietaris com als arrendataris, i s'ha apostat per la promoció d'habitatges de protecció en aquest règim, amb especial èmfasi a la ciutat de Barcelona. D'altra banda, la cultura de compra, fortament arrelada al nostre país, ha provocat que la solidaritat familiar es doni en el cas de comprar un pis, però no es plantegi tant sovint en el cas d'estar de lloguer. Així, el fet d'anar de lloguer com a pas intermedi entre viure a casa dels pares i comprar-ne un pis és molt poc freqüent en aquest grup d'edat i resulta especialment difícil en el cas que es vulgui viure de forma independent.

El règim de propietat també va associat a una determinada composició de la llar.

Figura 5: Règim de tinença de l'habitatge de la població emancipada de 25 a 34 anys, segons tipologia de la llar (2006)

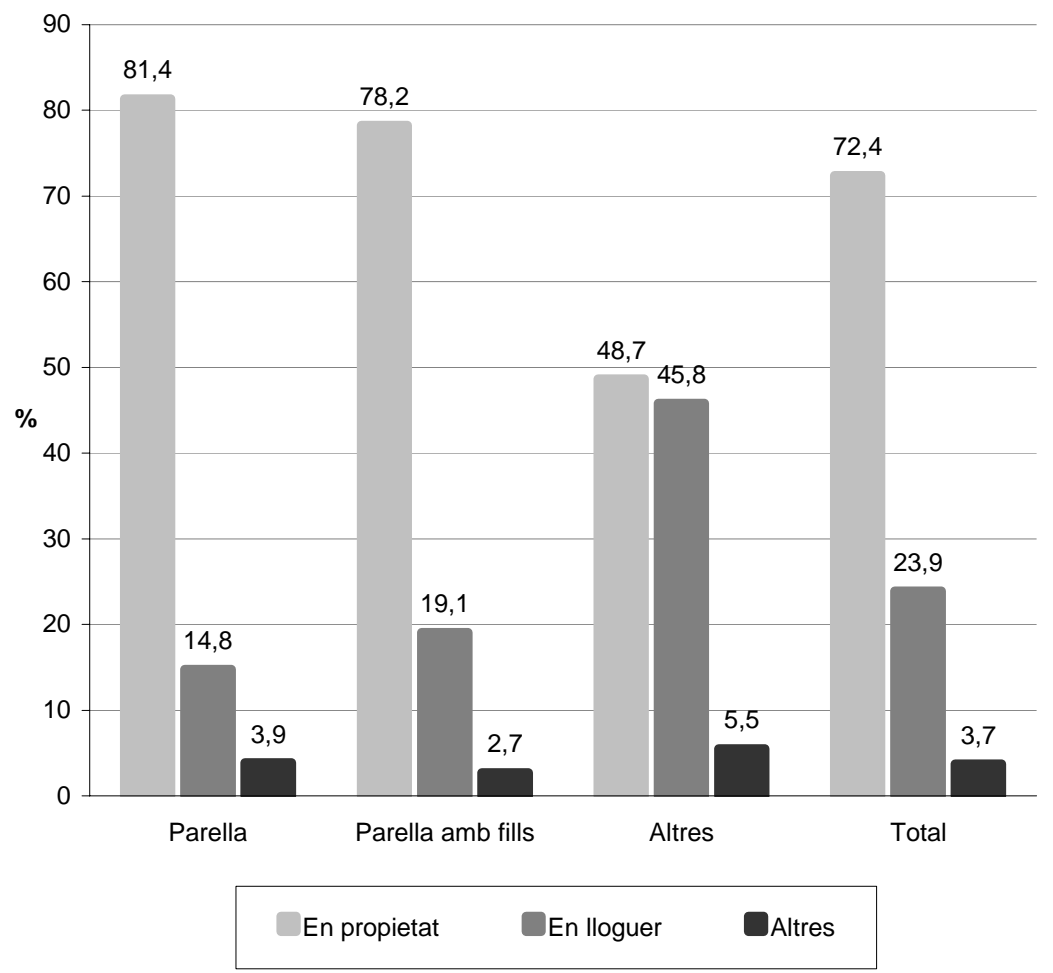

Font: Enquesta de condicions de vida i hàbits de la població (2006), IERMB

A la figura 5 s'observa com els que viuen en parella, que són el grup predominant, ho fan majoritàriament en habitatges de propietat, mentre que prop de la meitat del conjunt dels que viuen en llars unipersonals, monoparentals, llars sense nucli o amb llars de dos o més nuclis, 
agrupats en la categoria altres, viuen en habitatges de lloguer. Com que ha augmentat el pes de les tipologies de llars no tradicionals (unipersonals i sense nucli) i de les monoparentals, es redueix la capacitat de compartir despeses, fet que incideix en l'augment de la població amb dificultats d'accés a l'habitatge. Precisament, una de les principals causes del creixement dels habitatges de lloguer en els primers anys del nou segle ha estat la major presència d'aquestes darreres tipologies de llars.

Un altre element relacionat amb les pautes culturals té a veure amb la percepció que la població jove té sobre l'emancipació i que en els darrers anys ha anat variant. Aquest canvi es pot veure a partir de l'evolució del motiu pel qual la població de 25 a 34 anys té previst emancipar-se.

Figura 6: Motiu pel qual la població de 25 a 34 anys de la Regió Metropolitana de Barcelona té previst emancipar-se

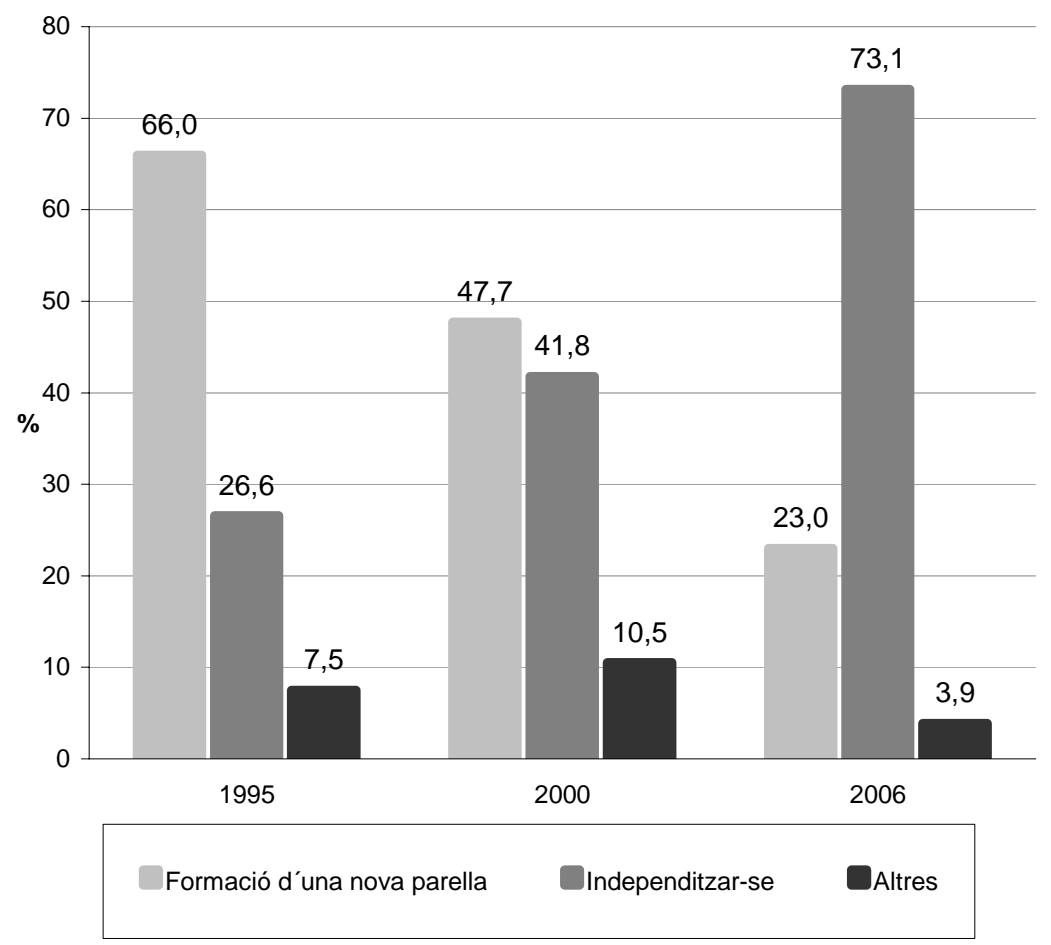

Font: Enquesta de condicions de vida i hàbits de la població (1995, 2000, 2006), IERMB

Com s'observa a la figura 6, mentre que el 1995 la majoria de la gent responia que tenia previst canviar d'habitatge per «anar a viure en parella», aquesta situació s'ha invertit i el 2006 la majoria de joves responia que el motiu era «independitzar-se». Algunes de les causes que han pogut provocar aquest canvi de percepció són la importància de la independència i d'unes pautes menys lligades a la formació d'una parella en la societat actual. 


\section{ELS HABITATGES DE LA POBLACIÓ JOVE-ADULTA EMANCIPADA}

La població jove-adulta de la Regió metropolitana de Barcelona viu generalment en habitatges de compra encara que últimament s'ha produït un descens d'aquest règim de tinença.

Figura 7: Règim de tinença de l'habitatge de la població emancipada de 25 a 34 anys de la Regió Metropolitana de Barcelona

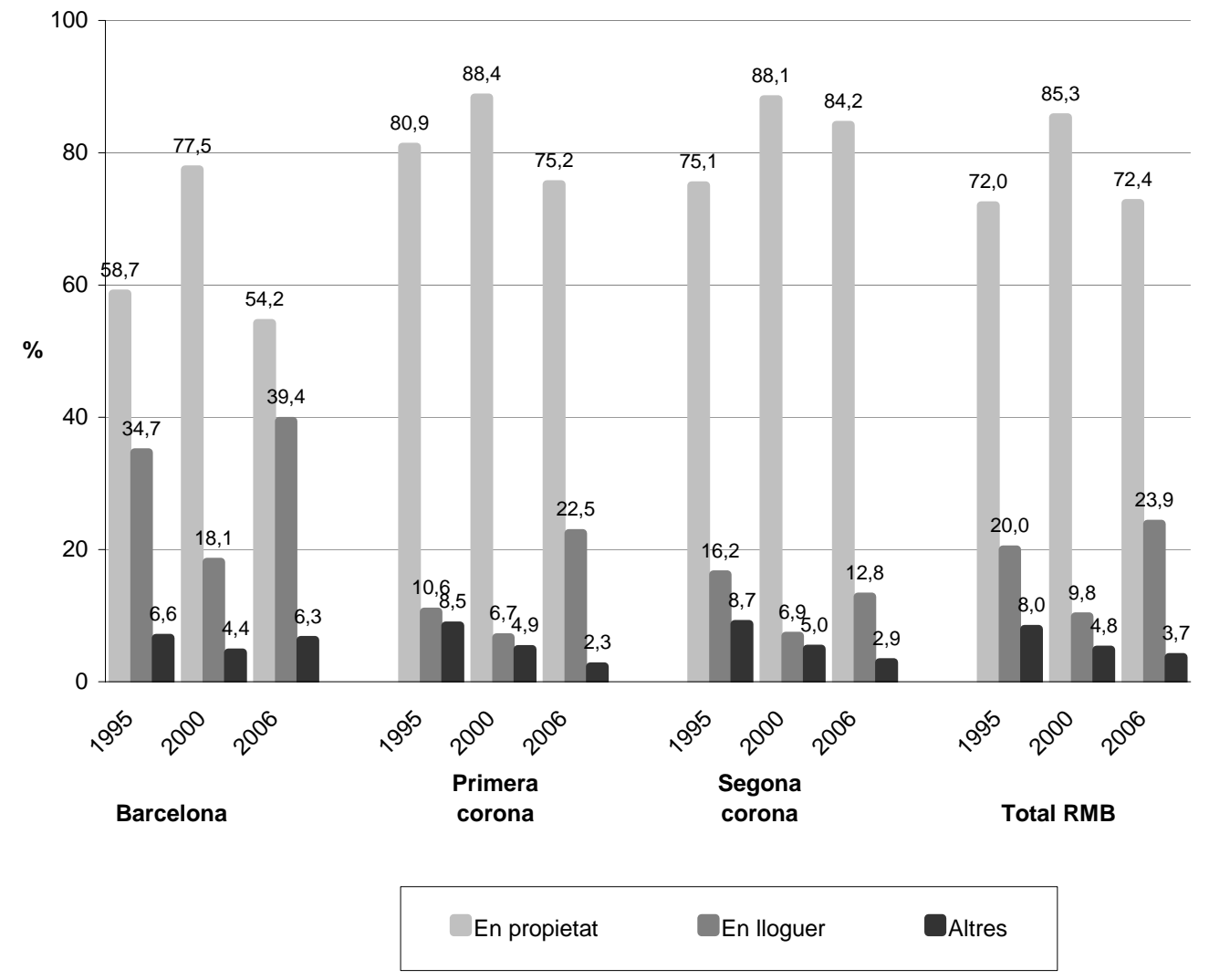

Font: Enquesta de condicions de vida i hàbits de la població (1995, 2000, 2006), IERMB

Com es pot veure a la figura 7, l'any 2000 un $85,3 \%$ dels joves emancipats de 25 a 34 anys vivien en un habitatge de compra i l'any 2006 aquest percentatge se situava en un 72,2\%. Així, l'any 2006, set de cada deu joves emancipats entre 25 i 34 anys vivien en habitatges de propietat, una proporció deu punts per sota de la del conjunt de la població.

Per completar l'anàlisi, es pot dir que és a Barcelona on el percentatge d'habitatges de lloguer entre la població jove-adulta emancipada és més elevat $(39,4 \%)$ i que va disminuint a mesura que ens allunyem de la ciutat central (22,5\% a la Primera corona, $12,8 \%$ a la Segona). En general, i a tots els àmbits, la gent jove viu més de lloguer que el conjunt de la població, si bé aquesta situació es dóna, sobretot, a Barcelona i a la Primera corona, on aquest percentatge és 
superior per als joves en 14 i 10,4 punts, respectivament. En el cas de la Segona corona la diferència és de tan sols 3,8 punts, i se situa en percentatges semblants als del conjunt de la població.

Taula 1: Règim de tinença de l'habitatge principal on viu la població (\%)

\begin{tabular}{|l|r|r|r|r|r|r|r|r|r|r|r|r|}
\hline & \multicolumn{3}{|c|}{ Barcelona } & \multicolumn{3}{|c|}{ Primera corona } & \multicolumn{3}{|c|}{ Segona corona } & \multicolumn{3}{|c|}{ Total RMB } \\
\cline { 2 - 12 } & 1995 & 2000 & 2006 & 1995 & 2000 & 2006 & 1995 & 2000 & 2006 & 1995 & 2000 & 2006 \\
\hline En propietat & 67,1 & 76,2 & 71,1 & 85,7 & 88,6 & 86,0 & 83,8 & 90,1 & 88,7 & 77,7 & 84,7 & 81,9 \\
\hline En lloguer & 30,2 & 21,8 & 25,4 & 11,6 & 9,5 & 12,1 & 13,1 & 7,5 & 9,0 & 19,5 & 13,2 & 15,5 \\
\hline Total & 100,0 & 100,0 & 100,0 & 100,0 & 100,0 & 100,0 & 100,0 & 100,0 & 100,0 & 100,0 & 100,0 & 100,0 \\
\hline
\end{tabular}

Font: Enquesta de condicions de vida i hàbits de la població (1995, 2000, 2006) , IERMB

Pel que fa a la superfície de l'habitatge, com es pot veure a la figura 8, la major part de la població emancipada de 25 a 34 anys de la Regió metropolitana vivia l'any 2006 en habitatges entre 61 i $80 \mathrm{~m}^{2}$ (el 41,3\%). En general, els habitatges dels joves-adults són més petits que els del conjunt dels ciutadans. Així, mentre que la meitat de la població viu en cases de més de 80 $\mathrm{m}^{2}$, en el cas del grup de 25 a 34 anys, aquest percentatge és aproximadament del $40 \%$. Aquesta és una qüestió preocupant, ja que es generalitza una tipologia d'habitatges poc reutilitzables i amb dimensions mínimes pel que fa als estàndards d'habitabilitat.

Figura 8: Superfície de l'habitatge de la població emancipada de 25 a 34 anys de la Regió Metropolitana de Barcelona

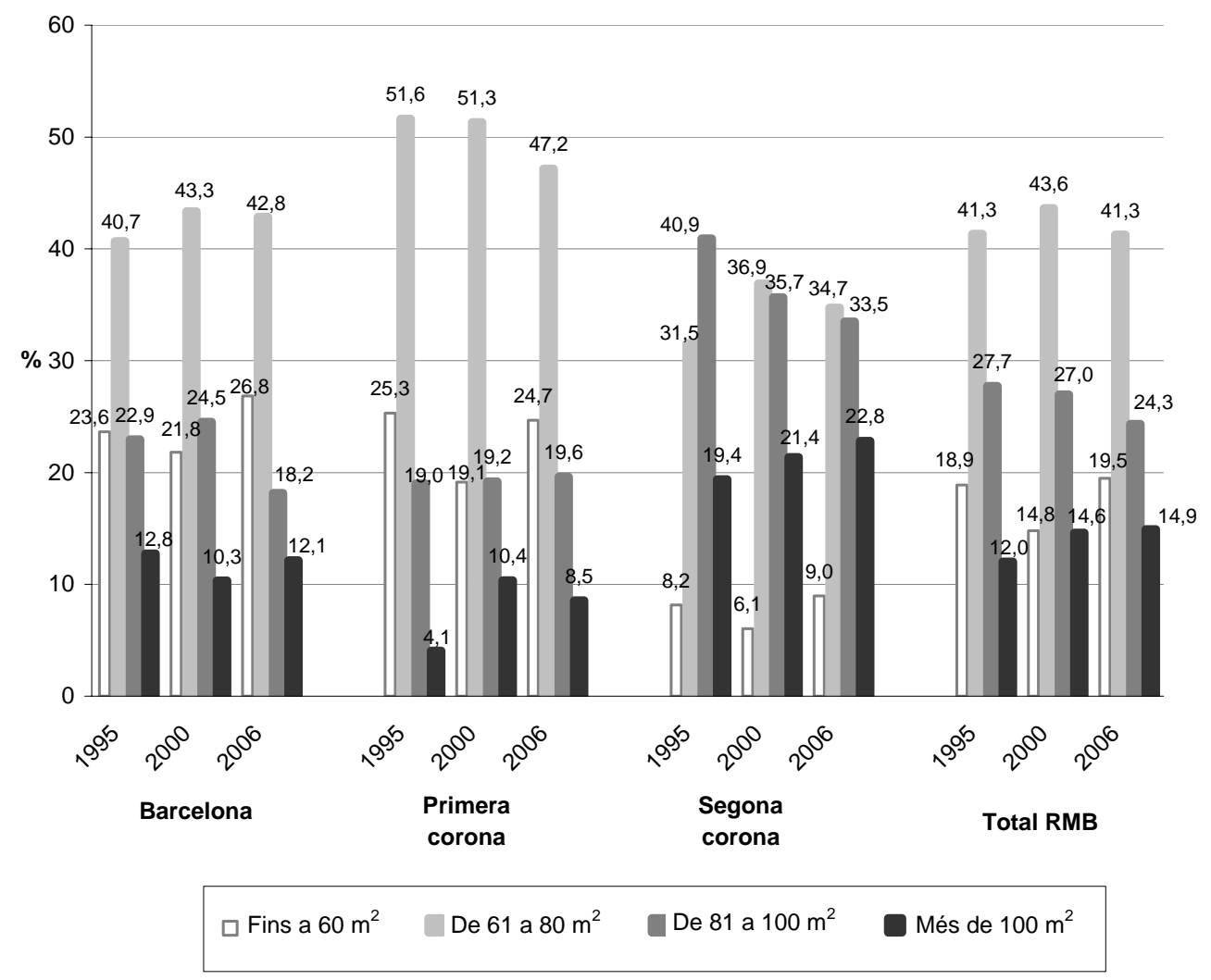

Font: Enquesta de condicions de vida i hàbits de la població $(1995,2000,2006)$, IERMB 
Si s'analitza l'evolució de la superfície dels habitatges de la població jove, s'observa que, a diferència del que succeeix al conjunt de la població, aquesta ha disminuït lleugerament en el darrer període. Com es pot veure a la figura 8, a la Regió metropolitana ha crescut la proporció de població de 25 a 34 anys que viu en llocs de menys de $60 \mathrm{~m}^{2}$ en detriment dels que tenen entre 60 i $100 \mathrm{~m}^{2}$, mentre que el percentatge que viu en habitatges de més de $100 \mathrm{~m}^{2} \mathrm{~s}$ 'ha mantingut pràcticament igual. Una de les causes es pot buscar en el fort augment dels preus dels habitatges que ha caracteritzat els primers anys dels segle XXI i que hauria provocat que una part d'aquest grup de població no hagués pogut accedir a residències de majors dimensions, sobretot als àmbits més centrals de la Regió metropolitana. Aquesta darrera qüestió, avalada per les respectives normatives urbanístiques, si es manté a mig termini pot acabar per generar un parc d'habitatges de reduïdes dimensions que empobrirà el teixit residencial metropolità.

En l'anàlisi per àmbits territorials es constata que a la Segona corona els habitatges dels joves tenen més superfície que no pas a Barcelona i a la Primera corona, una característica que també es dóna en el conjunt de la població.

Taula 2: Superfície de l'habitatge principal on viu la població (\%)

\begin{tabular}{|l|r|r|r|r|r|r|r|r|r|r|r|r|}
\hline & \multicolumn{3}{|c|}{ Barcelona } & \multicolumn{3}{|c|}{ Primera corona } & \multicolumn{3}{c|}{ Segona corona } & \multicolumn{3}{c|}{ Total RMB } \\
\cline { 2 - 14 } & \multicolumn{1}{|c|}{1995} & 2000 & 2006 & 1995 & 2000 & 2006 & 1995 & 2000 & 2006 & 1995 & 2000 & 2006 \\
\hline Fins a $60 \mathrm{~m}^{2}$ & 19,5 & 16,6 & 17,2 & 21,2 & 17,0 & 18,4 & 6,2 & 4,0 & 4,7 & 16,1 & 12,6 & 13,2 \\
\hline De 61 a $80 \mathrm{~m}^{2}$ & 34,4 & 35,7 & 38,3 & 48,5 & 48,4 & 42,8 & 25,0 & 28,2 & 27,4 & 36,0 & 37,3 & 35,8 \\
\hline De 81 a $100 \mathrm{~m}^{2}$ & 26,5 & 26,1 & 25,3 & 19,4 & 20,8 & 23,0 & 33,2 & 32,7 & 29,7 & 26,3 & 26,6 & 26,1 \\
\hline Mes de 100 m & 19,6 & 21,6 & 19,2 & 10,8 & 13,9 & 15,9 & 35,6 & 35,1 & 38,3 & 21,6 & 23,6 & 24,9 \\
\hline Total & 100,0 & 100,0 & 100,0 & 100,0 & 100,0 & 100,0 & 100,0 & 100,0 & 100,0 & 100,0 & 100,0 & 100,0 \\
\hline
\end{tabular}

Font: Enquesta de condicions de vida i hàbits de la població $(1995,2000,2006)$, IERMB

Mentre que a aquests dos darrers àmbits aproximadament un $70 \%$ dels joves viu en cases de menys de $80 \mathrm{~m}^{2}$, a la Segona corona aquest percentatge se situa vint-i-cinc punts per sota, al voltant del $45 \%$. Lògicament, en els habitatges de més de $80 \mathrm{~m}^{2}$, es dóna la situació contrària. Entre aquests, destaquen especialment les diferències en els de més de $100 \mathrm{~m}^{2}$, ja que mentre que a la Segona corona més d'un $20 \%$ dels joves-adults viu en llocs que tenen aquestes dimensions, a Barcelona i a la Primera corona aquest percentatge es redueix a la meitat.

Una altra de les característiques interessants és l'antiguitat de l'habitatge. Una primera idea que s'obté de les dades de la figura 9 és que hi ha més població jove-adulta que viu en habitatges dels anys seixanta i setanta (el $44,4 \%$ ) que no pas en els més nous, és a dir els que es van construir després del 1980 (el 39\%).

Si es comparen aquests valors amb els del conjunt de la població, s'observa que els habitatges dels joves-adults són lleugerament més nous, encara que les diferències no són especialment significatives. Tot plegat indica que una bona part dels habitatges més recents no ha estat ocupada per la població jove sinó per població adulta que canvia d'habitatge per anar a un de més nou. 
Figura 9: Antiguitat de l'habitatge de la població emancipada de 25 a 34 anys de la Regió Metropolitana de Barcelona (2006)

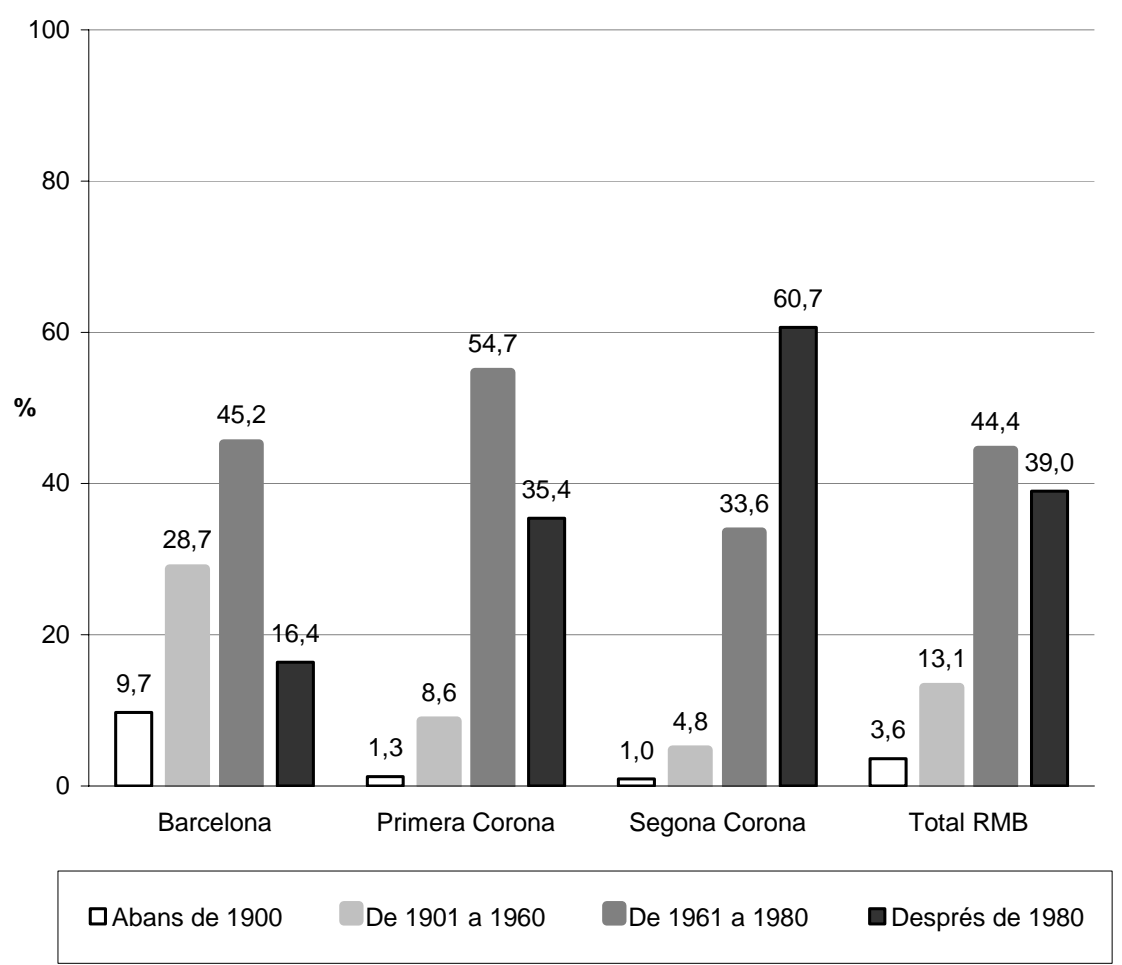

Font: Enquesta de condicions de vida i hàbits de la població (2006), IERMB

Taula 3: Any de construcció de l'habitatge principal on viu la població. 2006 (\%)

\begin{tabular}{|l|r|r|r|r|}
\hline & Barcelona & $\begin{array}{c}\text { Primera } \\
\text { corona }\end{array}$ & $\begin{array}{c}\text { Segona } \\
\text { corona }\end{array}$ & Total RMB \\
\hline Abans de 1900 & 8,7 & 1,5 & 3,3 & 4,6 \\
\hline De 1901 a 1960 & 28,3 & 10,4 & 10,6 & 16,7 \\
\hline De 1961 a 1980 & 47,4 & 59,0 & 40,5 & 48,5 \\
\hline Després de 1980 & 15,5 & 29,1 & 45,6 & 30,2 \\
\hline Total & 100,0 & 100,0 & 100,0 & 100,0 \\
\hline
\end{tabular}

Font: Enquesta de condicions de vida i hàbits de la població (2006) , IERMB

L'anàlisi per corones metropolitanes introdueix matisos importants a l'argument anterior, ja que s'observa que aquesta situació es dóna sobretot a Barcelona i a la Primera corona, i molt menys a la segona. Primer de tot cal tenir present que, en general i com succeeix al conjunt de la població, a mesura que ens allunyem del centre metropolità els habitatges de la població jove-adulta són més nous. El més interessant, però, s'obté quan es comparen els valors d'aquests dos col-lectius. Així, a Barcelona hi ha pràcticament el mateix percentatge de població jove-adulta vivint en habitatges nous que si es considera el conjunt de la població (el $16,4 \%$ i el 15,8\%, respectivament). A la Primera corona aquesta relació és cinc punts favorable per a la població jove (el $35,4 \%$ i el $29,3 \%$, respectivament), i a la segona ja ho és en 15 punts 
(el $60,7 \%$ i el $45,6 \%$, respectivament). És a dir, a mesura que ens allunyem de Barcelona la població jove-adulta viu en cases més noves i, a més, ho fa en uns percentatges superiors a la resta de la població. De tot plegat es pot deduir que els habitatges més nous són més accessibles per a la població jove com més lluny s'està del centre metropolità.

Pel que fa als inconvenients de l'habitatge, en general els joves estan més insatisfets que el conjunt de la població, i la manca d'espai és el principal motiu. Si bé al voltant del $40 \%$ del total de la població declara que no té cap inconvenient amb el seu habitatge, entre la població emancipada de 25 a 34 anys aquest percentatge se situa prop del $30 \%$. Tal com s'observa a la figura 10, a la Regió metropolitana, la manca d'espai apareix com el principal inconvenient, al voltant d'un $18,5 \%{ }^{11}$. Per tant, hi ha una correspondència entre la percepció sobre la manca d'espai i la situació real pel que fa a la superfície de l'habitatge. En aquest sentit, cal tenir present que la dimensió reduïda de l'espai dels nous habitatges està propiciada per dos factors que, amb les condicions actuals, difícilment poden variar de tendència. El primer es deu a l'augment del preu per metre quadrat $\mathrm{i}$ el segon a les normatives urbanístiques que estan afavorint la construcció de pisos més petits. El cas de la Regió metropolitana no és excepcional, ja que aquesta situació s'ha produït en els darrers anys a les principals metròpolis europees. El segon inconvenient més citat pels joves és, com en el total de població, la manca d'ascensor (11,5\%).

Figura 10: Principal inconvenient de l'habitatge de la població emancipada de 25 a 34 anys de la Regió Metropolitana de Barcelona (2006)*

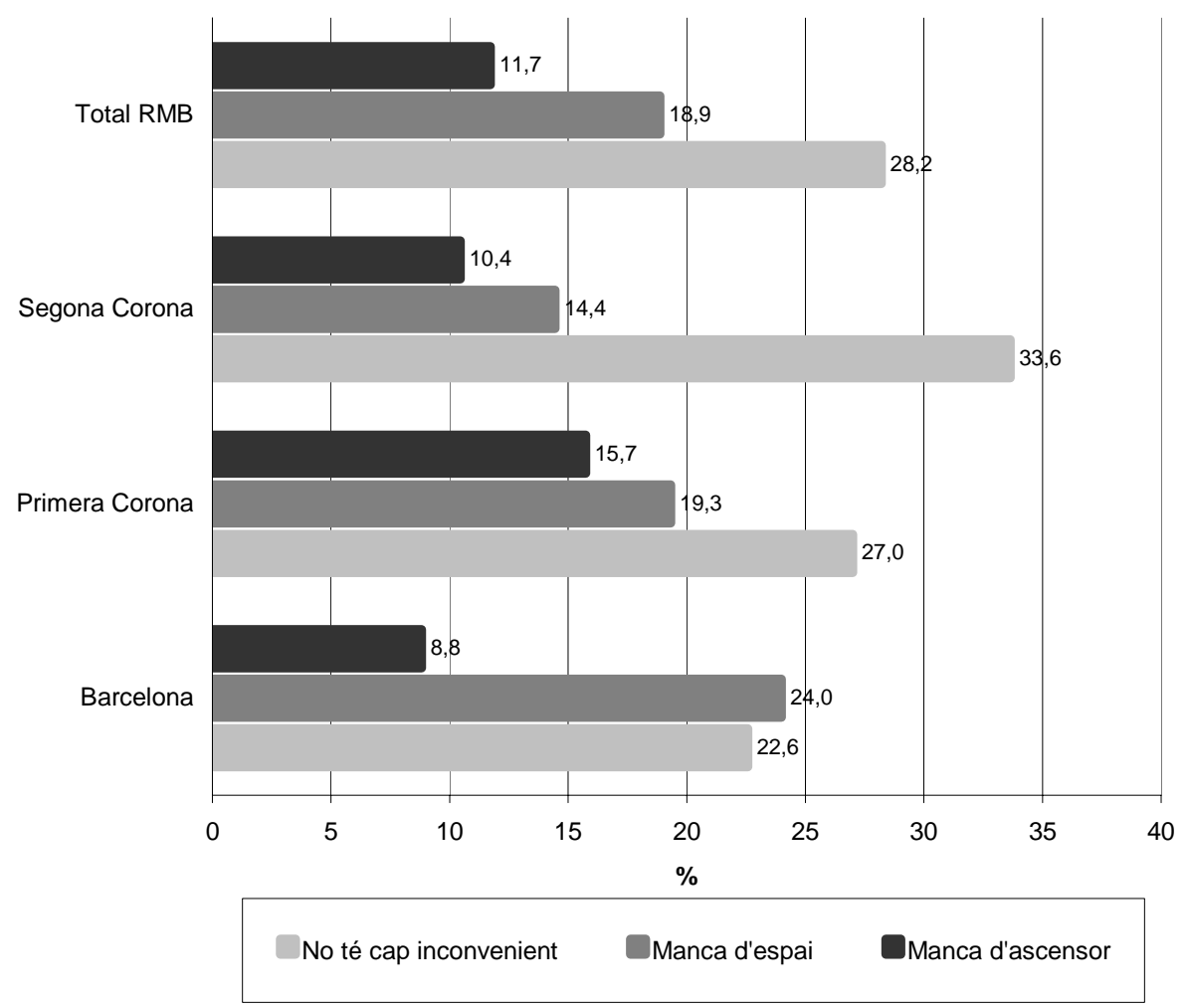

Font: Enquesta de condicions de vida i hàbits de la població (2006), IERMB

* S'inclouen només les tres principals respostes

\footnotetext{
${ }^{11}$ La manca d'espai també és el principal inconvenient del conjunt de la població, però amb un valor més baix, de l' $11,9 \%$.
} 
L'anàlisi per corones mostra que el percentatge més elevat de gent jove-adulta emancipada que troba en la manca d'espai el principal inconvenient de l'habitatge és a Barcelona, amb un $24,0 \%$. A la Primera corona aquest percentatge és del 19,3\% i a la segona del 14,4\%. La manca d'ascensor, segon inconvenient més declarat, presenta els percentatges més elevats a la Primera corona, amb un $15,7 \%$ i la Segona, amb un $10,4 \%$.

\section{CONCLUSIONS}

Un dels trets més característics de la població jove són les taxes d'emancipació, que malgrat l'estabilització en els darrers anys, continuen essent força baixes. Així, nou de cada deu joves de 18 a 24 anys, un de cada dos de 25 a 29, i un de cada cinc de 30 a 34, encara no estan emancipats. Si bé entre el col-lectiu més jove aquests valors s'han de relacionar, sobretot, amb l'allargament dels estudis i amb el retardament en la incorporació al mercat laboral, entre la població jove-adulta les principals causes s'han de buscar en la combinació de diversos factors: la precarietat laboral que caracteritza a una part d'aquest col-lectiu, l'esforç econòmic necessari per accedir a un habitatge, el dèficit acumulat d'aquests amb algun règim de protecció i la importància de la propietat a la nostra cultura, entre els més importants.

Tanmateix, aquest grup de població no es pot considerar com un col-lectiu uniforme, ni en els aspectes referents a l'esforç econòmic ni en la seva mobilitat residencial. Així, per exemple, mentre que aproximadament la meitat dels joves-adults té uns ingressos mensuals per sota dels mil euros, un $15 \%$ no té cap despesa per pagament de l'habitatge. Respecte a la mobilitat residencial, els contrastos també són importants. Així, mentre que la meitat dels joves de 25 a 29 encara no s'han emancipat, un de cada vuit ja han realitzat almenys el seu segon canvi d'habitatge, per millorar. Entre els de 30 a 34 anys, un de cada cinc encara no s'han emancipat, però un de cada quatre també ha realitzat almenys el seu segon canvi d'habitatge.

Un cop s'han emancipat, els joves de la regió metropolitana de Barcelona, en general, viuen en habitatges lleugerament més petits, més nous i amb els mateixos equipaments que el conjunt de la població. Amb tot, estan més insatisfets, principalment per la manca d'espai. El règim de tinença predominant és la propietat (el 72\%), encara que en uns percentatges inferiors que els del conjunt de la població.

Quan s'analitzen les diferències dels habitatges dels joves segons l'àmbit de residència, es reprodueix el que s'observa en el conjunt de la població, és a dir, els joves-adults que viuen a la Segona corona ho fan en espais més grans que els de Barcelona i la Primera corona. La manca de metres quadrats com a principal inconvenient s'accentua més com més a prop s'està del centre metropolità (el 24\% a Barcelona, el 19\% a la Primera corona, el $14 \%$ a la Segona). Per tant, hi ha una correspondència entre la percepció i la situació real pel que fa a la superfície de l'habitatge. A mesura que ens allunyem del centre metropolità els habitatges són, en general, més nous, i la propietat és clarament predominant sobre el lloguer (a Barcelona el 55\% en propietat, a la Primera corona el $75 \%$ i a la Segona corona el $85 \%$ ). 


\section{BIBLIOGRAFIA}

Àrea Metropolitana de Barcelona (2007) Revista de l'Àrea Metropolitana de Barcelona, Barcelona, AMB.

COSTAS, Anton (dir.) (2007) El llibre blanc de l'habitatge a Barcelona, Barcelona, Ajuntament de Barcelona.

LEAL, Jesús i CORTÉS, Luís (1998) La dimensión de la ciudad, Madrid, Centro de Investigaciones Sociológicas.

MIRALLES-GUASCH, Carme; DONAT, Carles; BARNADA, Jaume (2007) Habitatge $i$ mobilitat residencial. Primeres dades de l'Enquesta de condicions de vida $i$ hàbits de la població de Catalunya, 2006. Papers. Regió Metropolitana de Barcelona. núm 46, Barcelona, Institut d'Estudis Regionals i Metropolitans de Barcelona.

ROCA, Joan (1998); “¿Reducción en la formación de nuevos hogares o redistribución metropolitana de los mismos?" a Vergés, R. (ed.); El precio de la vivienda y la formación del hogar, Barcelona, Centre de Cultura Contemporània 
Architecture, City, and Environment

Arquitectura, Ciudad y Entorno 